\title{
A risk score for predicting postoperative complications in non-intubated thoracic surgery
}

\author{
Lan Lan ${ }^{1 \#}$, Long Jiang ${ }^{2,3}$, Chongyang Duan ${ }^{4}$, Weixiang Lu ${ }^{2,3}$, Canzhou Zhang ${ }^{1}$, Yanyi Cen ${ }^{1}$, Jianxing $\mathrm{He}^{2,3}$ \\ ${ }^{1}$ Department of Anesthesiology, The First Affiliated Hospital of Guangzhou Medical University, Guangzhou, China; ${ }^{2}$ Department of Cardiothoracic \\ Surgery, the First Affiliated Hospital of Guangzhou Medical University, Guangzhou, China; ${ }^{3}$ Guangzhou Institute of Respiratory Disease \& \\ China State Key Laboratory of Respiratory Disease, Guangzhou, China; ${ }^{4}$ Department of Biostatistics, School of Public Health, Southern Medical \\ University, Guangzhou, China \\ Contributions: (I) Conception and design: L Lan; (II) Administrative support: J He; (III) Provision of study materials or patients: L Jiang; (IV) \\ Collection and assembly of data: W Lu, C Zhang, Y Cen; (V) Data analysis and interpretation: C Duan; (VI) Manuscript writing: All authors; (VII) \\ Final approval of manuscript: All authors. \\ "These authors contributed equally to this work. \\ Correspondence to: Jianxing He. Department of Cardiothoracic Surgery, The First Affiliated Hospital of Guangzhou Medical University, and \\ Guangzhou Institute of Respiratory Disease \& China State Key Laboratory of Respiratory Disease, Guangzhou 510620, China. \\ Email: drhe_jianxing@163.com.
}

Background: The risk factors for postoperative complications in non-intubated video-assisted thoracoscopic surgery (VATS) have not been observed before. Here to develop a simple risk score to predict the risk of postoperative complications for patients who scheduling non-intubated VATS, which is beneficial to guide the clinical interventions.

Methods: A total of 1,837 patients who underwent non-intubated VATS were included from January 2011 to December 2018. A development data set and a validation data set were allocated according to an approximate 3:2 ratio of total cases. The stepwise logistic regression was used to establish a risk score model, and the methods of bootstrap and split-sample were used for validation.

Results: Multivariable analysis revealed that the forced expiratory volume in the first second in percent of predicted, the anesthesia method, blood loss, surgical time, and preoperative neutrophil ratio were risk factors for postoperative complications. The risk score was established with these 5 factors, varied from 0 to 53 , with the corresponding predicted probability of postoperative complications occurrence ranged from $1 \%$ to $92 \%$ and was calibrated (Hosmer-Lemeshow $\chi^{2}=6.261 ; \mathrm{P}=0.618$ ). Good discrimination was acquired in the development and validation data sets (C-statistic 0.705 and 0.700$)$. A positive correlation was between the risk score and postoperative complications ( $\mathrm{P}$ for trend $<0.01)$. Three levels of low-risk $(0-15$ points], moderate-risk (15-30 points], and high-risk (>30 points] were established based on the score distribution of postoperative complications.

Conclusions: This simple risk score model based on risk factors of postoperative complications can validly identify the high-risk patients with postoperative complications in the non-intubated VATS, and allow for early interventions.

Keywords: Postoperative complication; risk score; non-intubated; video-assisted thoracoscopic surgery (VATS)

Submitted Apr 12, 2021. Accepted for publication May 20, 2021.

doi: $10.21037 /$ jtd-21-636

View this article at: https://dx.doi.org/10.21037/jtd-21-636

(c) Journal of Thoracic Disease. All rights reserved. 


\section{Introduction}

At the end of the 1800s, the first attempts of anesthesia in thoracic surgery were made by non-intubated patients with spontaneous breathing air-ether through a mask (1). With the development of pulmonary isolation techniques and mechanical ventilation, the intubated thoracic anesthesia became mainstream. However, in recent years, non-intubated video-assisted thoracoscopic surgery (VATS) had been successfully performed in different types of procedures (2-6).

VATS surgery under non-intubated anesthesia decreased the duration of surgery and postoperative hospital stay (7), and improved recovery with fewer postoperative complications (PC) $(2-4,8)$. At present, the surgical procedures and anesthesia techniques of non-intubated VATS had been described clearly (9-11), but it still lacks specific observations for perioperative complications. The postoperative clinical complications are the most concerning issues to postoperative rehabilitation. However, risk factors of PC in non-intubated VATS had not been reported before. Moreover, this question cannot be easy to answer. The reason is not only the majority of publications on non-intubated VATS came from scattered and different medical centers, with inevitably different selection criteria for patients, but also most of them were small sample observations. Hence, since non-intubated VATS has gradually gained popularity in the past two decades, and no clinical risk model of predicting PC has been established at present. It is necessary to explicit the risk factors of PC and accurately allows for timely interventions for the high-risk patients.

Hereupon, through this observation, the primary outcome was to find out the risk factors for PC and develop a convenient and accurate risk score to identify the highrisk patients with PC in non-intubated VATS.

We present the following article in accordance with the TRIPOD reporting checklist (available at https://dx.doi. org/10.21037/jtd-21-636).

\section{Methods}

\section{Study design}

We conducted a post hoc reanalysis of a large singlecenter retrospective cohort. The data collectors were blind to the primary outcome. The analysis included patients who successfully underwent VATS with non-intubated anesthesia from January 1st, 2011, to December 30th, 2018 at the Guangzhou Institute of Respiratory Diseases. The inclusion for non-intubated VATS is the same as described before (12-14), which patients were age $\geq 18$ years, with body mass index (BMI) $\leq 25$, the American Society of Anesthesiologists (ASA) physical status III or less, with no abnormal airway and spinal anatomy, no compromised coagulation, no serious cardiopulmonary dysfunction, and no extensive pleural adhesion. Patients were excluded from this observation if they proceeded to overlapping operations besides lungs, thoracotomy, tracheal surgery, esophagus surgery, and emergency surgery. Patients who had invalid or unavailable preoperative basic examination results and incomplete intraoperative and postoperative medical records were also excluded.

\section{Main operating procedures}

All patients received VATS under non-intubated anesthesia $(12,15)$. Two anesthesia methods were initiated in our institution, one was plasma concentration targetcontrolled infusion (TCI) of propofol and remifentanil, combined with intravenous dexmedetomidine and placed with laryngeal mask airway (LMA), the other method was epidural anesthesia (EA), which maintained anesthesia with ropivacaine with placing the epidural catheter in the fifth or seventh epidural space. It was up to the patients, the experience of surgeons and anesthesiologists to decided which anesthesia method to choose.

The thoracoscopic procedures were consistent with the guidelines of the American Association for Thoracic Surgery (16). Whether to place a chest-drainage tube or not depends on the patient's condition and surgical procedures. All thoracic procedures were divided into five types, such as nonanatomic wedge resection, including wedge resection, bullectomy, and lung volume reduction surgery; the anatomic resection, including lobectomy and segmentectomy; the mediastinal mass resection; bilateral sympathectomy; and other procedures, including thoracoscopic exploration, lung biopsy, pericardial cyst resection, etc. Surgical time was defined as the interval from skin cutting to wound suturing and a surgical dressing covering. After the operation, the patients were removed LMA or epidural catheter and sent back to the ward, or transfer to the intensive care unit (ICU). If the patient did not place a drainage tube or enter the ICU, the duration of chest drainage and ICU stay were recorded as zero. 


\section{Primary endpoint and candidate predictors}

The primary endpoint was PC. The minor PC included: pleural effusion, dyspnea, arrhythmia, air leakage, fever, while the major PC included: reoperation, chylothorax, mechanical ventilation, cardio-dysfunction, pulmonary embolism, and death. According to the definition of Clavien-Dindo classification (17), pleural effusion, air leakage and fever are belonged to Grade I, dyspnea and arrhythmia are belonged to Grade II, reoperation and chylothorax are belonged to Grade III, mechanical ventilation and pulmonary embolism are belonged to Grade $\mathrm{IV}$, cardio-dysfunction is belonged to Grade IVa, the death of patient is belonged to Grade $\mathrm{V}$.

The candidate predictors included preoperative characteristics and intraoperative variables, such as age, gender, BMI, the level of ASA physical status, the previous medical history, Revised Cardiac Risk Index (RCRI), stair climbing, values of the forced vital capacity in percent of predicted (FVC\% predicted), and the forced expiratory volume in the first second in percent of predicted $\left(\mathrm{FEV}_{1} \%\right.$ predicted), left ventricular ejection fraction (LVEF), types of thoracic procedures, surgical location, preoperative values of leukocyte and neutrophil ratio, anesthesia methods, surgery time, blood loss, intraoperative values of minimum pulse oxygen saturation $\left(\mathrm{SpO}_{2}\right)$ and arterial partial pressure of carbon dioxide $\left(\mathrm{PaCO}_{2}\right)$.

\section{Statistical analysis}

Statistical analyses of patient distribution were performed with SAS software version 9.2. All analyses were based on the input of complete cases.

All eligible patients were allocated on the ratio of $3: 2$, and a development data set and a validation data set were established respectively. A risk model and a risk score model were established according to the development data set. In univariate analysis, $\mathrm{P}<0.05$ candidate predictors were included in the development of the risk model. The best subset of risk factors was selected by the bootstrap method to avoid over-fitting. The scoring method of the risk score model was similar to Sullivan's (18) and was based on the development of the risk model. Continuous variables were classified as clinical significant categories for scoring purposes. Pearson's contingency coefficient evaluated the degree of correlation between the score levels and the PC risk, and the Cochran-Armitage test was used to examine the trend.

The predictive accuracy of the risk model and the risk score model was assessed by both discriminations measured by the C-statistic and calibration evaluated by the HosmerLemeshow c2 statistic and calibration plot. Furthermore, the risk scoring model was validated by split-sample to evaluate the stability of the model. The area under the receiver operating characteristic (ROC) curve was compared by the nonparametric approach of DeLong (19).

\section{Ethical statement}

The study was conducted in accordance with the Declaration of Helsinki (as revised in 2013). The study was approved on November 5th, 2019 by the Medical Ethics Committee of the first affiliated hospital of Guangzhou Medical University (No. K-51) before data were accessed and individual consent for this retrospective analysis was waived.

\section{Results}

A total of 1,837 patients who underwent non-intubated thoracic surgery were included (Figure 1, Table S1).

\section{Risk model and risk score development}

A total of 157 (9\%) experienced PC among the 1,837 patients. One hundred and one of 1,097 patients experienced PC in the development data set, while 56 of 740 patients experienced PC in the validation data set (Tables S2,S3). After variables selected by a bootstrap technique, the $\mathrm{FEV}_{1} \%$ predicted, anesthesia method, blood loss, surgical time, and preoperative neutrophil ratio were selected as the best subset of risk factors to establish a risk model (Table 1). The scores of all predictors were shown in Table 2.

\section{Risk score validation}

The risk score model was applied to the development data set for discrimination, with a C-statistic of $0.705(95 \%$ CI: $0.650-0.759)$ and high calibration with a $\chi^{2}$ statistic of $6.261(\mathrm{P}=0.618)$ (Figure 2). The validation results of the split-sample, which based on the validation data set, were similar to those of the development data set, with an average C-statistic of 0.700 (95\% CI: 0.619-0.781) and high calibration with a $\chi^{2}$ statistic of $7.963(\mathrm{P}=0.437)$ (Figure 2). The ROC (Figure 2) and the PC proportions (Figure 3) from the development and validation data sets were consistent with each other. The predicted incidence of PC 


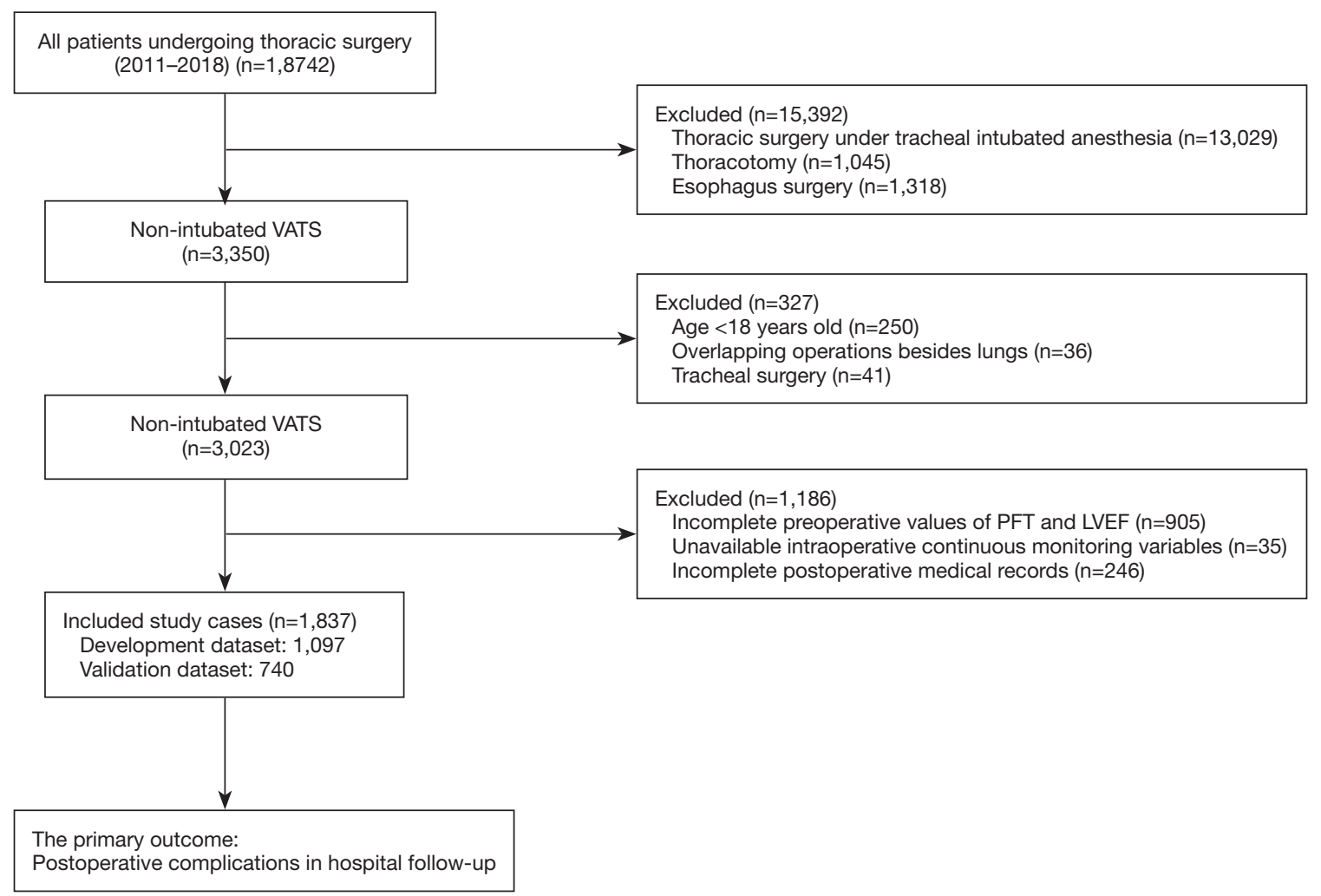

Figure 1 The flow chart of this observation. VATS, video-assisted thoracoscopic surgery; PFT, pulmonary function test; LVEF, left ventricular ejection fraction.

Table 1 Univariate and multivariable logistic regression analysis of risk factors that were selected to develop the risk model for predicting postoperative complications (developmental data set, $\mathrm{n}=1,097$ )

\begin{tabular}{|c|c|c|c|c|c|c|}
\hline Variable & \multicolumn{3}{|c|}{ Univariate analysis } & \multicolumn{3}{|c|}{ Multivariable analysis } \\
\hline $\mathrm{FVE}_{1} \%$ predicted & 0.982 & 0.972 to 0.992 & 0.000 & 0.977 & 0.966 to 0.987 & 0.000 \\
\hline Anesthesia method (EA vs. TCI + LMA) & 2.165 & 1.396 to 3.356 & 0.001 & 2.092 & 1.316 to 3.326 & 0.002 \\
\hline Blood loss & 1.003 & 1.001 to 1.004 & 0.000 & 1.002 & 1.001 to 1.003 & 0.006 \\
\hline Preoperative neutrophil ratio & 1.025 & 1.005 to 1.045 & 0.015 & 1.021 & 1.001 to 1.042 & 0.041 \\
\hline
\end{tabular}

*, the natural logarithmic transformations of surgery time were made because of their extreme positive skewness. $\mathrm{FEV}_{1} \%$ predicted, the forced expiratory volume in the first second in percent of predicted; EA, epidural anesthesia; TCI, target controlled infusion; LMA, laryngeal mask airway; OR, odds ratio; $\mathrm{Cl}$, confidence interval.

was nicely corresponding to the observed (Figure 3).

\section{Clinical implications of the risk score model}

Based on the risk score model, the risk scores were classified into three levels for clinical use (Figure 4). The definitions of three levels were low-risk (0-15 points], moderate-risk (15-30 points], and high-risk ( $>30$ points], which was based on the score distribution of PC (Figure 3). The total risk score varied from the minimum 0 (lowest risk) to the maximum 53 (highest risk) (Table 2), and the corresponding predicted probability of PC occurrence ranged from $1 \%$ to $92 \%$. The 
Table 2 Risk scores for all predicting variables

\begin{tabular}{|c|c|}
\hline Risk factors & Score \\
\hline \multicolumn{2}{|c|}{$\mathrm{FVE}_{1} \%$ predicted } \\
\hline$\geq 80 \%$ & 0 \\
\hline $70-79 \%$ & 2.5 \\
\hline $60-69 \%$ & 5 \\
\hline $50-59 \%$ & 7.5 \\
\hline $35-49 \%$ & 10 \\
\hline$<35 \%$ & 15 \\
\hline \multicolumn{2}{|c|}{ Preoperative neutrophil ratio } \\
\hline$<40 \%$ & 0 \\
\hline $40-49 \%$ & 2 \\
\hline $50-59 \%$ & 4 \\
\hline $60-69 \%$ & 6 \\
\hline $70-79 \%$ & 8 \\
\hline$\geq 80 \%$ & 10 \\
\hline \multicolumn{2}{|l|}{ Surgical time } \\
\hline$<30 \min$ & 0 \\
\hline 30-59 min & 4.5 \\
\hline $60-119 \min$ & 9 \\
\hline $120-239 \mathrm{~min}$ & 13.5 \\
\hline$\geq 240 \mathrm{~min}$ & 18 \\
\hline \multicolumn{2}{|l|}{ Blood loss } \\
\hline$\leq 50 \mathrm{~mL}$ & 0 \\
\hline $51-100 \mathrm{~mL}$ & 1 \\
\hline $101-200 \mathrm{~mL}$ & 3 \\
\hline$>200 \mathrm{~mL}$ & 6 \\
\hline \multicolumn{2}{|c|}{ Anesthesia method } \\
\hline $\mathrm{TCl}+\mathrm{LMA}$ & 0 \\
\hline EA & 4 \\
\hline
\end{tabular}

$\mathrm{FEV}_{1} \%$ predicted, the forced expiratory volume in the first second in percent of predicted; $\mathrm{TCl}$, target controlled infusion; LMA, laryngeal mask airway; EA, epidural anesthesia.

relationship of risk level and predicted risk of PC were low-risk (1-6\%), moderate-risk (7-33\%), high-risk (36-92\%) (Table 3).

\section{Discussion}

In this observation, we established and validated a risk score model based on 5 available factors $\left(\mathrm{FEV}_{1} \%\right.$ predicted, preoperative neutrophil ratio, surgical time, blood loss, and anesthesia method), to predict the risk of PC in nonintubated VATS. And we provided three classifications of low, moderate, and higher-risk levels of post-operative complications for the clinicians to use. Predicting PC through preoperative and intraoperative variables is the original intention. This recommended a convenient risk score allows for the identification of high-risk patients immediately and makes the right risk allocation, finally initiates early treatments.

Non-intubated VATS has been applied to a large number of patients in a series of observations, such as Klijian's report under awake VATS (20), Chen's experience in lung resection, and Hung's studies in the thoracoscopic lobectomy (11,21-23). However, no specific perioperative complications have been proposed in these observations. In our previous studies, eligibility criteria for non-intubated VATS were strictly identified, but the occurrence of PC still existed (12-14). Based on this observation, the incidence of PC was $9 \%$, and we could speculate that the $\mathrm{FEV}_{1} \%$ predicted, the anesthesia method, the blood loss, the surgical time, and the preoperative neutrophil ratio were the risk factors of PC. It has been proved that poor pulmonary function and a longer surgical time can increase PC (24-26), and EA with high plane block can retardant the movement of intercostal muscles and reduce the inspiratory capacity $(27,28)$, which can lead to hypercapnia and hypoxia. Therefore, it requires initiating timely interventions for high-risk patients and proceed with personality procedures in non-intubated VATS.

Of note, PC prolonged the hospital stay and increased unfavorable clinical outcomes, which are contrary to the rapid rehabilitation paraded by non-intubated VATS. A practical and efficacious method for avoiding complications is its early identification and prevention. Therefore, the establishment of a risk score model to detect PC earlier is immediately needed in non-intubated VATS. In this observation, the proposed risk score revealed a high degree of differentiation and good calibration both in the development and validation data sets, and the predictive power of the risk score for PC was higher. Moreover, the quantitative variables in our risk model may be more objective, which comes from a large number of clinical cases of non-intubated VATS in our institution.

Non-intubated VATS are usually practiced in simple surgical procedures for which intubated anesthesia is deemed more complex and thus unnecessary, such as 

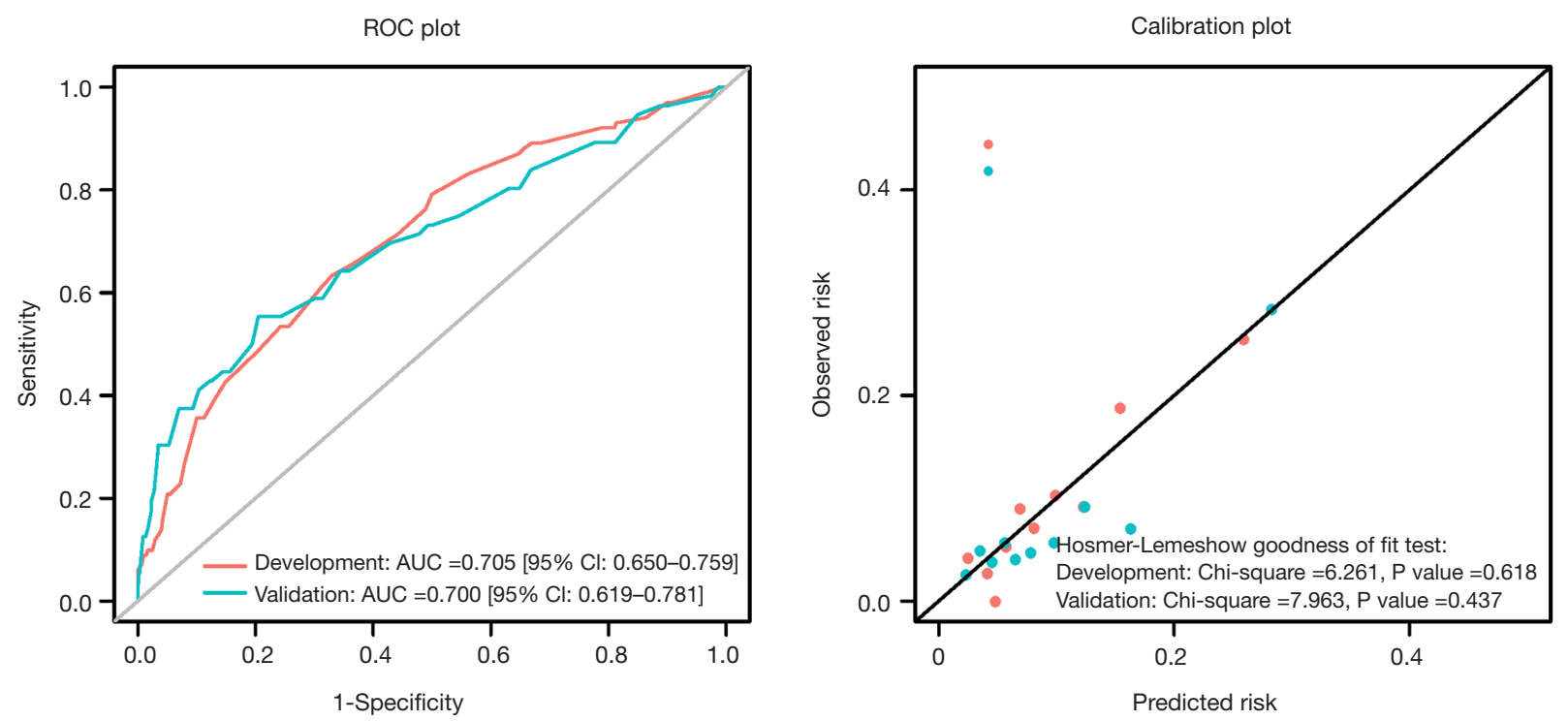

Figure 2 The area under the ROC curves and calibration plot with the Hosmer-Lemeshow test for goodness-of-fit result for the risk score. ROC, receiver operator characteristic.

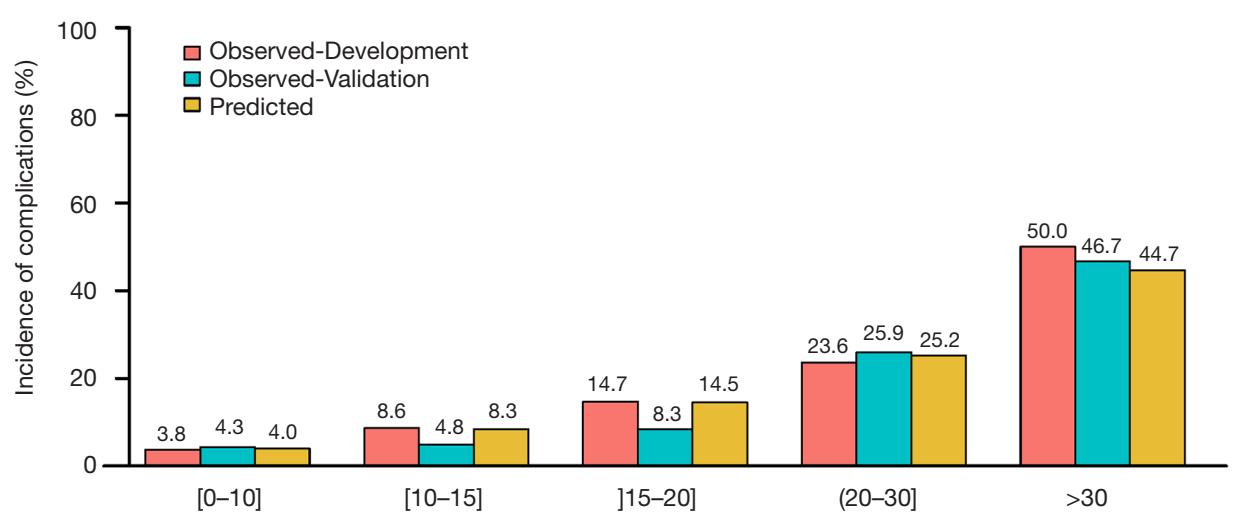

Figure 3 The correlation of PC with the risk score. Increasing the risk of PC with increasing risk score is showed in the development and validation data sets. The observed incidence of PC was consistent with the predicted ones based on the data set risk score. PC, postoperative complications.

treatment of spontaneous pneumothorax, recurrent pleural effusion, pleural, pulmonary and mediastinal biopsy, and sympathectomy, etc. $(2,4,8)$; on the other, non-intubated VATS are preferred in some cases which are deemed at higher risk for standard intubated anesthesia, such as patients with compromised pulmonary function, older age, associated cardiovascular comorbidity $(5,10,29)$. It's in brief that the advantage of non-intubated VAST outweighs the disadvantage for some high-risk patients, and the intraoperative factors can significantly affect the postoperative rehabilitation of patients. Licker proposes that prolonged surgery is an independent risk factor for predicting PC (30), and that was why we included intraoperative factors to establish the risk score model. In our risk score, the ability to predict was more comprehensive by combining with four other factors. If the score is less than 15 , the risk level of PC is low-risk, the patient can be directly transferred to the ward, and just receive routine treatment after the operation, such as atomization and pulmonary function training, without 


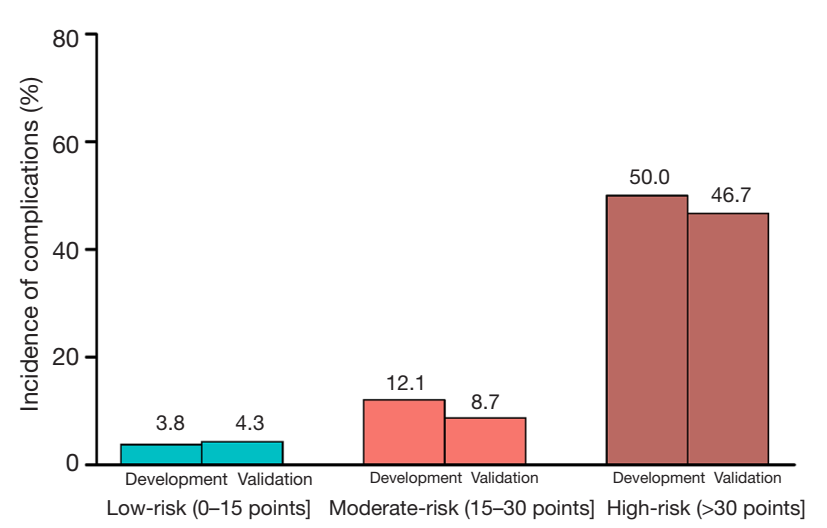

Figure 4 The correlation of risk level with the range of risk score.

Table 3 The relationship between risk level and predicted risks of postoperative complications

\begin{tabular}{lcc}
\hline Risk level & Risk score level (points) & Predicted risk (\%) \\
\hline Low-risk & $0-15$ & $1-6$ \\
Moderate-risk & $>15-30$ & $7-33$ \\
High-risk & $>30$ & $36-92$ \\
\hline
\end{tabular}

placement of chest drainage tube, and whether the use of postoperative analgesia is depending on personal need. If the score is $>15-30$, the risk level of postoperative complication is medium risk, in addition to routine treatments, the patient continues to use pre-operative drugs, such as antiasthmatics and expectorants, and they should be placed chest drainage tube after the operation. If the score is more than 30 , the risk level of postoperative complication is high risk, the patient not only initiates the therapies the same as in medium risk level, but also should be placed chest-tube drainage longer, receive intensive care and monitoring in the ICU, and need more chest-radiography and laboratory examination for postoperative evaluation.

\section{Limitations}

Undoubtedly, this study has several limitations. First, this investigation proceeded in a single-center, and its results may be limited to the non-intubated populations. But it can avoid the study bias coming from different training programs of surgeons and different protocols of management and therapy in multi-center. Second, patients without values of pulmonary function and LVEF (such as patients with pneumothorax or intolerance of pulmonary function test) were excluded from this study, which resulted in a lack of data analysis for such non-intubated VATS patients. However, pulmonary function and LVEF are important indexes for preoperative evaluation of thoracic surgery, thus the established risk score model should be included in the patients with these results. Third, this model was verified by the split-sample method. It is a simple way to examine the overfitting, and cannot determine the generalizability of independent cohorts. Fourth, this risk model was based on different types of surgical procedures which may result in a heterogeneity of comparison, but it would make the risk model more in accordance with the actual clinical practice, since non-intubated VATS has been applied in a wide range of thoracoscopic procedures. And we also proved the feasibility of this risk model by analyzing the subgroup of different types of surgical procedures (Table S4). Fifth, the diffusing capacity of the lung for carbon monoxide (DLCO) had not been included in the analysis. The reasons were that, firstly, DLCO was not a routine examination for every patient in our institute; secondly, if DLCO were included in the analysis, the results may be bias due to removal of many cases without DLCO.

\section{Conclusions}

In summary, the preoperative evaluations should be rigorous on patients scheduled for non-intubated VATS. This simple risk score model, which is based on five available factors $\left(\mathrm{FEV}_{1} \%\right.$ predicted, preoperative neutrophil ratio, surgical time, blood loss, and anesthesia method), is a valid tool for the identification of high-risk patients with PC in non-intubated thoracic surgery. This could help clinicians to distinguish the high-risk patients and initiate the appropriate and earlier interventions for them.

\section{Acknowledgments}

We are grateful to the help of Dr. Xiaohui Wen and Dr. Qinglong Dong for the support of clinical data collecting and thank for the contributions of all the participants in this observation.

Funding: None.

\section{Footnote}

Reporting Checklist: The authors have completed the TRIPOD reporting checklist. Available at https://dx.doi. org/10.21037/jtd-21-636 
Data Sharing Statement: Available at https://dx.doi. org/10.21037/jtd-21-636

Peer Review File: Available at https://dx.doi.org/10.21037/ jtd-21-636

Conflicts of Interest: All authors have completed the ICMJE uniform disclosure form (available at https://dx.doi. org/10.21037/jtd-21-636). JH serves as the Executive Editor-in-Chief of Fournal of Thoracic Disease. The other authors have no conflicts of interest to declare.

Ethical Statement: The authors are accountable for all aspects of the work in ensuring that questions related to the accuracy or integrity of any part of the work are appropriately investigated and resolved. The study was conducted in accordance with the Declaration of Helsinki (as revised in 2013). The study was approved on November 5th, 2019 by the Medical Ethics Committee of the first affiliated hospital of Guangzhou Medical University (No. K-51) before data were accessed and individual consent for this retrospective analysis was waived.

Open Access Statement: This is an Open Access article distributed in accordance with the Creative Commons Attribution-NonCommercial-NoDerivs 4.0 International License (CC BY-NC-ND 4.0), which permits the noncommercial replication and distribution of the article with the strict proviso that no changes or edits are made and the original work is properly cited (including links to both the formal publication through the relevant DOI and the license). See: https://creativecommons.org/licenses/by-nc-nd/4.0/.

\section{References}

1. Slinger P. Anesthesia for non-intubated thoracic surgery. In: Slinger P. editior. Principles and Practice of Anesthesia for Thoracic Surgery. 2nd edition. Springer Nature Switzerland AG, 2019:425-7.

2. Pompeo E, Mineo D, Rogliani P, et al. Feasibility and results of awake thoracoscopic resection of solitary pulmonary nodules. Ann Thorac Surg 2004;78:1761-8.

3. Wang ML, Hung MH, Hsu HH, et al. Non-intubated thoracoscopic surgery for lung cancer in patients with impaired pulmonary function. Ann Transl Med 2019;7:40.

4. Pompeo E, Tacconi F, Frasca L, et al. Awake thoracoscopic bullaplasty. Eur J Cardiothorac Surg 2011;39:1012-7.

5. Vladimir C, Zdenek K, Lukas F, et al. Clarification of the resection line non-intubated segmentectomy using indocyanine green. Ann Transl Med 2019;7:38.

6. AlGhamdi ZM, Ahn S, Kim KC, et al. Non-intubated uniportal VATS surgery is feasible approach. J Thorac Dis 2020;12:1147-50.

7. Deng HY, Zhu ZJ, Wang YC, et al. Non-intubated video-assisted thoracoscopic surgery under loco-regional anesthesia for thoracic surgery: a meta-analysis. Interact Cardiovasc Thorac Surg 2016;23:31-40.

8. Li S, Jiang L, Ang KL, et al. New tubeless video-assisted thoracoscopic surgery for small pulmonary nodules. Eur J Cardiothorac Surg 2017;51:689-93.

9. Sunaga H, Blasberg J, Heerdt P. Anesthesia for nonintubated video-assisted thoracic surgery. Curr Opin Anaesthesiol 2017;30:1-6.

10. Iwata Y, Hamai Y, Koyama T. Anesthetic management of non-intubated video-assisted thoracoscopic surgery using epidural anesthesia and dexmedetomidine in three patients with severe respiratory dysfunction. J Anesth 2016;30:324-7.

11. Hung MH, Chan KC, Liu YJ, et al. Nonintubated thoracoscopic lobectomy for lung cancer using epidural anesthesia and intercostal blockade: A retrospective cohort study of 238 cases. Medicine (Baltimore) 2015;94:e727.

12. Lan L, Cen Y, Zhang C, et al. A propensity score-matched analysis for non-intubated thoracic surgery. Med Sci Monit 2018;24:8081-7.

13. Guo Z, Yin W, Wang W, et al. Spontaneous ventilation anaesthesia: total intravenous anaesthesia with local anaesthesia or thoracic epidural anaesthesia for thoracoscopic bullectomy. Eur J Cardiothorac Surg 2016;50: 927-32.

14. Liu J, Cui F, Pompeo E, et al. The impact of nonintubated versus intubated anaesthesia on early outcomes of video-assisted thoracoscopic anatomical resection in non-small-cell lung cancer: A propensity score matching analysis. Eur J Cardiothorac Surg 2016;50:920-25.

15. Dong Q, Liang L, Li Y, et al. Anaesthesia with nontracheal intubation in thoracic surgery. J Thorac Dis 2012;4:126-30.

16. Svensson LG, Gillinov AM, Weisel RD, et al. The American Association for Thoracic Surgery Consensus Guidelines: Reasons and purpose. J Thorac Cardiovasc Surg 2016;151:935-9.e1.

17. Bolliger M, Kroehnert JA, Molineus F, et al. Experiences with the standardized classifification of surgical complications (Clavien-Dindo) in general surgery patients. Eur Surg 2018;50:256-61.

18. Sullivan LM, Massaro JM, D'Agostino RB Sr. Presentation of multivariate data for clinical use: The Framingham 
Study risk score functions. Stat Med 2004;23:1631-60.

19. DeLong ER, DeLong DM, Clarke-Pearson DL.

Comparing the areas under two or more correlated receiver operating characteristic curves: a nonparametric approach. Biometrics 1988;44:837-45.

20. Klijian AS, Gibbs M, Andonian NT. AVATS: Awake Video-Assisted Thoracic Surgery--extended series report. J Cardiothorac Surg 2014;9:149.

21. Chen KC, Cheng YJ, Hung MH, et al. Nonintubated thoracoscopic lung resection: a 3-year experience with 285 cases in a single institution. J Thorac Dis 2012;4:347-51.

22. Chen KC, Cheng YJ, Hung MH, et al. Nonintubated thoracoscopic surgery using regional anesthesia and vagal block and targeted sedation. J Thorac Dis 2014;6:31-6.

23. Hung MH, Hsu HH, Chan KC, et al. Non-intubated thoracoscopic surgery using internal intercostal nerve block, vagal block and targeted sedation. Eur J Cardiothorac Surg 2014;46:620-5.

24. Kearney DJ, Lee TH, Reilly JJ, et al. Assessment of operative risk in patients undergoing lung resection. Importance of predicted pulmonary function. Chest

Cite this article as: Lan L, Jiang L, Duan C, Lu W, Zhang $\mathrm{C}$, Cen $\mathrm{Y}, \mathrm{He}$ J. A risk score for predicting postoperative complications in non-intubated thoracic surgery. J Thorac Dis 2021;13(7):3960-3968. doi: 10.21037/jtd-21-636
1994;105:753-59.

25. Chetta A, Tzani P, Marangio E, et al. Respiratory effects of surgery and pulmonary function testing in the preoperative evaluation. Acta Biomed 2006;77:69-74.

26. Kim ES, Kim YT, Kang CH, et al. Prevalence of and risk factors for postoperative pulmonary complications after lung cancer surgery in patients with early-stage COPD. Int J Chron Obstruct Pulmon Dis 2016;11:1317-26.

27. Sundberg A, Wattwil M, Arvill A. Respiratory effects of high thoracic epidural anaesthesia. Acta Anaesthesiol Scand 1986;30:215-7.

28. Groeben H. Epidural anesthesia and pulmonary function. J Anesth 2006;20:290-9.

29. Mineo TC, Pompeo E, Mineo D, et al. Awake nonresectional lung volume reduction surgery. Ann Surg 2006;243:131-36

30. Licker M, Spiliopoulos A, Frey JG, et al. Management and outcome of patients undergoing thoracic surgery in a regional chest medical centre. Eur J Anaesthesiol 2001;18:540-7. 
Table S1 Patient's characteristics distribution between non-PC group and PC group

\begin{tabular}{|c|c|c|c|c|}
\hline Variables & Total cases $(n=1,837)$ & Non-PC group $(n=1,680)$ & ) $P C$ group $(n=157)$ & P value \\
\hline Median age, years & $50.40 \pm 13.70$ & $50.06 \pm 13.63$ & $54.08 \pm 13.96$ & $<0.001$ \\
\hline Gender, $\mathrm{n}(\%)$ & & & & 0.017 \\
\hline Male & 945 (51) & $850(51)$ & $95(61)$ & \\
\hline Female & $892(49)$ & $830(49)$ & $62(39)$ & \\
\hline BMI $\left(\mathrm{kg} / \mathrm{m}^{2}\right)$ & $22.31 \pm 2.80$ & $22.35 \pm 2.79$ & $21.90 \pm 2.95$ & 0.054 \\
\hline ASA physical status, $\mathrm{n}(\%)$ & & & & 0.023 \\
\hline 1 & $1,378(75)$ & $1,272(76)$ & $106(68)$ & \\
\hline$\|$ & $416(23)$ & $370(22)$ & $46(29)$ & \\
\hline III & $43(2)$ & 38 (2) & $5(3)$ & \\
\hline \multicolumn{5}{|l|}{ Previous medical history, $\mathrm{n}(\%)$} \\
\hline Smoking history & $350(19)$ & $316(19)$ & 34 (22) & 0.385 \\
\hline Cardiovascular disease & $185(10)$ & $162(10)$ & $23(15)$ & 0.046 \\
\hline Diabetes & $71(4)$ & $64(4)$ & $7(5)$ & 0.687 \\
\hline Pulmonary operation history & 44 (2) & 41 (2) & 3 (2) & 0.678 \\
\hline Pulmonary disease & 105 (6) & 95 (6) & 10 (6) & 0.712 \\
\hline Hepatic dysfunction & $31(2)$ & 31 (2) & 0 & 0.086 \\
\hline Neurologic diseases & 40 (2) & 35 (2) & $5(3)$ & 0.366 \\
\hline Non-pulmonary cancer & $67(4)$ & $63(4)$ & $4(3)$ & 0.442 \\
\hline RCRI, n (\%) & & & & 0.648 \\
\hline 1 point & $1,819(99)$ & $1,663(99)$ & $156(99)$ & \\
\hline 2 points & $18(1)$ & $17(1)$ & $1(1)$ & \\
\hline Stair climbing, $\mathrm{n}(\%)$ & & & & $<0.001$ \\
\hline$\geq 22 \mathrm{~m}$ & $1,807(98)$ & $1,659(99)$ & $148(94)$ & \\
\hline$<22 \mathrm{~m}$ & $30(2)$ & $21(1)$ & $9(6)$ & \\
\hline LVEF (\%) & $71.23 \pm 5.20$ & $71.24 \pm 5.16$ & $71.15 \pm 5.64$ & 0.844 \\
\hline \multicolumn{5}{|l|}{ Pulmonary function tests $(\%)$} \\
\hline $\mathrm{FVE}_{1} \%$ predicted & $92.84 \pm 18.49$ & $93.44 \pm 18.01$ & $86.17 \pm 22.03$ & $<0.001$ \\
\hline FVC\% predicted & $95.15 \pm 18.38$ & $95.70 \pm 18.10$ & $89.27 \pm 20.24$ & $<0.001$ \\
\hline $\mathrm{FEV}_{1} / \mathrm{FVC} \%$ predicted & $96.94 \pm 11.93$ & $97.23 \pm 11.27$ & $93.86 \pm 17.25$ & 0.001 \\
\hline Types of thoracic procedure, $n(\%)$ & & & & 0.839 \\
\hline Non-anatomical lung surgery & $978(53)$ & $896(53)$ & $82(52)$ & \\
\hline Anatomical lung surgery & $577(31)$ & $520(31)$ & $57(36)$ & \\
\hline Mediastinal mass resection & $157(9)$ & $148(9)$ & $9(6)$ & \\
\hline Bilateral sympathectomy & 59 (3) & $56(4)$ & 3 (2) & \\
\hline Other surgery & $66(4)$ & $60(3)$ & $6(4)$ & \\
\hline Surgical location, $n(\%)$ & & & & 0.313 \\
\hline Left lung & $734(40)$ & $668(40)$ & 66 (42) & \\
\hline Right lung & $883(48)$ & $805(48)$ & $78(50)$ & \\
\hline Mediastinum & $207(11)$ & $195(11)$ & $12(7)$ & \\
\hline Left and right lung & $13(1)$ & $12(1)$ & 1 (1) & \\
\hline Surgical time (min) & $95(60,145)$ & $95(60,140)$ & $135(70,185)$ & $<0.001$ \\
\hline Blood loss (mL) & $20(10,50)$ & $20(10,50)$ & $35(10,100)$ & $<0.001$ \\
\hline Anesthesia methods, $\mathrm{n}(\%)$ & & & & $<0.001$ \\
\hline $\mathrm{TCl}+\mathrm{LMA}$ & $1,450(79)$ & $1,346(80)$ & $104(66)$ & \\
\hline EA & $387(21)$ & $334(20)$ & $53(34)$ & \\
\hline Intraoperative minimum $\mathrm{SpO}_{2}(\%)$ & $97.49 \pm 3.01$ & $97.49 \pm 3.0$ & $97.42 \pm 3.19$ & 0.771 \\
\hline Level of intraoperative $\mathrm{SpO}_{2}, \mathrm{n}(\%)$ & & & & 0.99 \\
\hline $94-100 \%$ & $1,660(91)$ & $1,518(91)$ & $142(90)$ & \\
\hline $90-93 \%$ & $151(8)$ & $140(8)$ & $11(7)$ & \\
\hline$<89 \%$ & 26 (1) & 22 (1) & $4(3)$ & \\
\hline Intraoperative maximum $\mathrm{PaCO}_{2}(\mathrm{mmHg}$ & ) $46.63 \pm 7.95$ & $46.50 \pm 7.91$ & $48.10 \pm 8.26$ & 0.016 \\
\hline Level of intraoperative $\mathrm{PaCO}_{2}, \mathrm{n}(\%)$ & & & & 0.013 \\
\hline $30-45 \mathrm{mmHg}$ & $996(54.2)$ & $926(55)$ & $70(45)$ & \\
\hline $46-60 \mathrm{mmHg}$ & $746(40.6)$ & $669(39.8)$ & $77(49)$ & \\
\hline $61-80 \mathrm{mmHg}$ & $92(5)$ & $82(5)$ & 10 (6) & \\
\hline$>81 \mathrm{mmHg}$ & $3(0.2)$ & $3(0.2)$ & 0 & \\
\hline Mean ICU stay (days) & $0(0,1)$ & $0(0,1)$ & $0(0,1)$ & $<0.001$ \\
\hline Duration of chest-tube drainage, $d$ & $2(0,3)$ & $2(0,3)$ & $6(3,8)$ & $<0.001$ \\
\hline Postoperative hospital stay (days) & $5(3,7)$ & $5(3,6)$ & $10(6,15)$ & $<0.001$ \\
\hline Preoperative leukocyte $\left(\times 10^{\circ}\right)$ & $6.57 \pm 2.0$ & $6.55 \pm 1.97$ & $6.80 \pm 2.24$ & 0.189 \\
\hline Preoperative neutrophil ratio (\%) & $58.75 \pm 9.88$ & $58.55 \pm 9.78$ & $60.93 \pm 10.72$ & 0.04 \\
\hline Postoperative leukocyte $\left(\times 10^{9}\right)$ & $10.94 \pm 3.65$ & $10.87 \pm 3.62$ & $11.68 \pm 3.84$ & 0.007 \\
\hline Postoperative neutrophil ratio (\%) & $80.01 \pm 11.08$ & $79.88 \pm 11.14$ & $81.35 \pm 10.42$ & 0.112 \\
\hline \multicolumn{4}{|c|}{ Postoperative complications based on Clavien-Dindo classification, $n(\%)$} & $<0.001$ \\
\hline None & $1,680(91.4)$ & 1,680 & 0 & \\
\hline \multicolumn{5}{|l|}{ Grade I } \\
\hline Pleural effusion & $106(5.8)$ & 0 & $106(67)$ & \\
\hline Air leakage in chest tube & $15(0.8)$ & 0 & $15(9)$ & \\
\hline Fever & $6(0.3)$ & 0 & $6(4)$ & \\
\hline \multicolumn{5}{|l|}{ Grade II } \\
\hline Arrhythmia & $5(0.3)$ & 0 & $5(3)$ & \\
\hline Dyspnea & $9(0.5)$ & 0 & $9(6)$ & \\
\hline Grade III & & & & \\
\hline Reoperation & $4(0.2)$ & 0 & $4(3)$ & \\
\hline Chylothorax & $4(0.2)$ & 0 & $4(3)$ & \\
\hline Grade IV & & & & \\
\hline Mechanical ventilation & $4(0.2)$ & 0 & $4(2)$ & \\
\hline Pulmonary embolism & $1(0.1)$ & 0 & 1 (1) & \\
\hline Grade IVa & & & & \\
\hline Cardio-dysfunction & $2(0.1)$ & 0 & 2 (1) & \\
\hline Grade V & & & & \\
\hline Death & $1(0.1)$ & 0 & 1 (1) & \\
\hline
\end{tabular}

Data are presented as mean \pm SD, median (25th, 75th percentiles) or $n$ (\%). PC, post-operative complication; BMl, body mass index; ASA American Society of Anesthesiologists; LVEF, left ventricular ejection fraction; RCRI, Revised Cardiac Risk Index; FVC\% predicted, the $\mathrm{TCl}$, target controlled infusion; $\mathrm{LMA}$, laryngeal mask airway; $\mathrm{EA}$, epidural anesthesia; $\mathrm{SpO}_{2}$, pulse oxygen saturation; $\mathrm{PaCO}_{2}$ arterial partia pressure of carbon dioxide. 
Table S2 The data distribution of postoperative complications

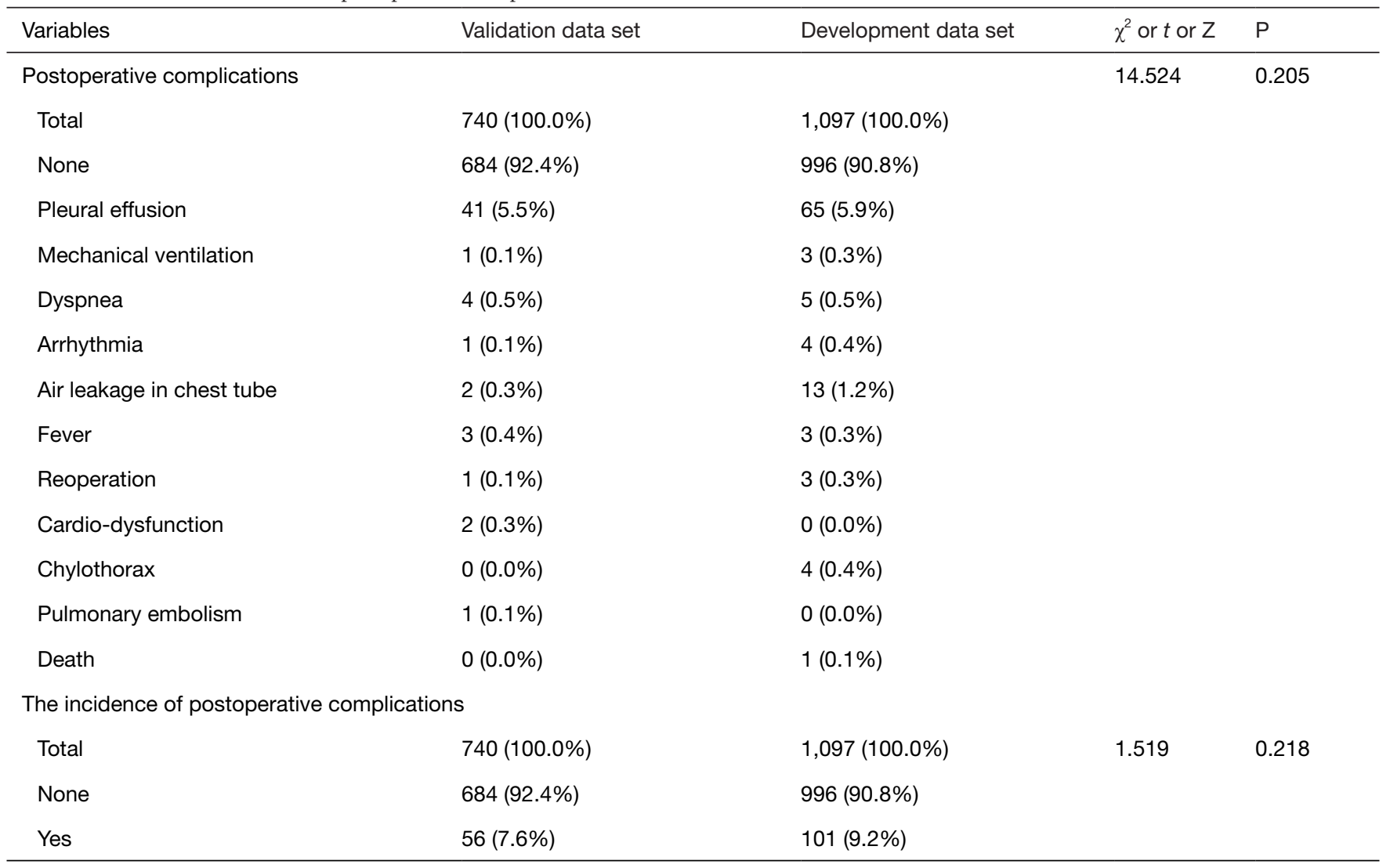




\begin{tabular}{|c|c|c|c|c|}
\hline Variables & Validation data set & Development data set & $\chi^{2}$ or $t$ or $Z$ & $\mathrm{P}$ \\
\hline Gender (male), n (\%) & $346(46.8 \%)$ & $546(49.8 \%)$ & 1.609 & 0.205 \\
\hline Smoking history, n (\%) & $138(18.6 \%)$ & $212(19.3 \%)$ & 0.131 & 0.717 \\
\hline Hypertension, n (\%) & $83(11.2 \%)$ & $102(9.3 \%)$ & 1.795 & 0.180 \\
\hline Diabetes, n (\%) & $30(4.1 \%)$ & $41(3.7 \%)$ & 0.119 & 0.730 \\
\hline Pulmonary operation history, $\mathrm{n}(\%)$ & $17(2.3 \%)$ & $27(2.5 \%)$ & 0.051 & 0.822 \\
\hline Pulmonary disease, $\mathrm{n}(\%)$ & $42(5.7 \%)$ & $63(5.7 \%)$ & 0.004 & 0.951 \\
\hline Non-pulmonary cancer, n (\%) & $22(3.0 \%)$ & $45(4.1 \%)$ & 1.603 & 0.205 \\
\hline Hepatic dysfunction, n (\%) & $10(1.4 \%)$ & $21(1.9 \%)$ & 0.844 & 0.358 \\
\hline Neurologic diseases, n (\%) & $21(2.8 \%)$ & $19(1.7 \%)$ & 2.537 & 0.111 \\
\hline Surgery types, n (\%) & & & 1.943 & 0.746 \\
\hline Non-anatomical lung surgery & $386(52.2 \%)$ & $592(54.0 \%)$ & & \\
\hline Anatomical lung surgery & $234(31.6 \%)$ & $343(31.3 \%)$ & & \\
\hline Mediastinal mass resection & $71(9.6 \%)$ & $86(7.8 \%)$ & & \\
\hline Bilateral sympathectomy & $26(3.5 \%)$ & $40(3.6 \%)$ & & \\
\hline Other procedures & $23(3.1 \%)$ & $36(3.3 \%)$ & & \\
\hline Surgery location, n (\%) & & & 1.507 & 0.681 \\
\hline Right lung & $359(48.5 \%)$ & $524(47.8 \%)$ & & \\
\hline Mediastinum & $89(12.0 \%)$ & $118(10.8 \%)$ & & \\
\hline Left and right lung & $4(0.5 \%)$ & $9(0.8 \%)$ & & \\
\hline RCRI, n (\%) & & & 0.131 & 0.718 \\
\hline 1 point & $732(98.9 \%)$ & $1087(99.1 \%)$ & & \\
\hline 2 points & $8(1.1 \%)$ & $10(0.9 \%)$ & & \\
\hline Stair climbing <22 m, n (\%) & $12(1.6 \%)$ & $18(1.6 \%)$ & 0.001 & 0.975 \\
\hline Anesthesia methods, n (\%) & & & 0.000 & 0.990 \\
\hline $\mathrm{TCl}+\mathrm{LMA}$ & $584(78.9 \%)$ & $866(78.9 \%)$ & & \\
\hline EA & $156(21.1 \%)$ & $231(21.1 \%)$ & & \\
\hline Age, years & $50.14 \pm 14.11$ & $50.58 \pm 13.41$ & -0.663 & 0.508 \\
\hline BMI, $\mathrm{kg} / \mathrm{m}^{2}$ & $22.42 \pm 2.81$ & $22.24 \pm 2.80$ & 1.322 & 0.186 \\
\hline $\mathrm{FEV}_{1}, \%$ & $95.50(83.92-105.04)$ & $94.19(83.34-105.00)$ & 0.719 & 0.472 \\
\hline FVC, \% & $96.54(85.40-107.00)$ & $95.94(85.00-106.74)$ & 0.595 & 0.552 \\
\hline $\mathrm{FEV}_{1} / \mathrm{FVC}, \%$ & $97.81(92.27-103.74)$ & 97.55 (92.04-103.56) & 0.738 & 0.461 \\
\hline LVEF, \% & $71.00(68.00-75.00)$ & $71.00(68.00-75.00)$ & -0.001 & 1.000 \\
\hline Preoperative leukocyte, $\times 10^{9}$ & $6.46(5.27-7.55)$ & $6.20(5.20-7.39)$ & 2.140 & 0.032 \\
\hline Preoperative neutrophil ratio, \% & $58.90(52.20-64.95)$ & $58.40(52.10-64.40)$ & 0.800 & 0.423 \\
\hline Surgery time, $\min$ & $97.50(60.00-145.00)$ & $95.00(60.00-147.50)$ & 0.148 & 0.883 \\
\hline Blood lose, $\mathrm{mL}$ & $20.00(10.00-50.00)$ & $20.00(10.00-50.00)$ & 0.286 & 0.775 \\
\hline $\mathrm{SpO}_{2}, \%$ & $98.00(96.00-100.00)$ & $98.00(97.00-100.00)$ & -1.773 & 0.076 \\
\hline $\mathrm{PaCO}_{2}, \mathrm{mmHg}$ & $45.00(42.00-50.00)$ & $45.00(41.00-50.00)$ & 1.360 & 0.174 \\
\hline Mean ICU stay, days & $0.00(0.00-1.00)$ & $0.00(0.00-1.00)$ & 0.262 & 0.793 \\
\hline Duration of chest-tube drainage, days & $2.00(0.00-3.00)$ & $2.00(0.00-3.00)$ & -1.840 & 0.066 \\
\hline Postoperative leukocyte, $\times 10^{9}$ & $10.78(8.47-12.96)$ & $10.55(8.50-12.90)$ & 0.272 & 0.785 \\
\hline Postoperative neutrophil ratio, $\%$ & $82.55(73.03-88.88)$ & $82.60(73.15-88.75)$ & -0.269 & 0.788 \\
\hline
\end{tabular}


Table S4 The subgroup comparisons of variables

\begin{tabular}{|c|c|c|c|c|c|c|}
\hline Subgroup & \multicolumn{3}{|c|}{ Development data set } & \multicolumn{3}{|c|}{ Validation data set } \\
\hline$<65$ & 0.7123 & 0.6484 & 0.7762 & 0.6515 & 0.5629 & 0.7400 \\
\hline$\geq 65$ & 0.6267 & 0.5096 & 0.7438 & 0.8901 & 0.7454 & 1.0000 \\
\hline 1 & 0.6804 & 0.6126 & 0.7483 & 0.6946 & 0.5912 & 0.7981 \\
\hline II & 0.7680 & 0.6858 & 0.8501 & 0.7056 & 0.5663 & 0.8450 \\
\hline III & 0.7063 & 0.2965 & 1.0000 & 0.7222 & 0.5093 & 0.9351 \\
\hline Mediastinal mass resection & 0.9042 & 0.8246 & 0.9838 & 0.8554 & 0.6764 & 1.0000 \\
\hline Bilateral sympathectomy & 0.9265 & 0.8400 & 1.0000 & 1.0000 & 1.0000 & 1.0000 \\
\hline Other procedures & 0.9688 & 0.9167 & 1.0000 & 0.8125 & 0.4319 & 1.0000 \\
\hline
\end{tabular}

(c) Journal of Thoracic Disease. All rights reserved. 